\title{
The Effect of Ice Cream Intake on Pain Relief for Patients After Tonsillectomy
}

\author{
Majid A. Albeladi ${ }^{1}$, Marzouqi A. Salamah ${ }^{1}$, Rayan Alhussaini ${ }^{2}$ \\ 1. Otolaryngology-Head and Neck Surgery, Ohud Hospital, Al-Madinah Al-Munawarah, SAU 2. Otolaryngology-Head \\ and Neck Surgery, Prince Mohammed Bin Abdulaziz Hospital - National Guard Health Affairs, Al-Madinah, SAU
}

Corresponding author: Majid A. Albeladi, dr.majid9@hotmail.com

\section{Abstract \\ Introduction}

The post-tonsillectomy pain can lead to a decrease in fluid and food intake, followed by dehydration, which can slow down the repair process and make pain control harder. Different groups of analgesics have their own side effects. Therefore, the consideration of non-pharmacological ways to control pain can be of great value such as ice cream and other cold drinks.

\section{Aim}

The purpose behind this study is to assess whether the use of ice cream after tonsillectomy with or without adenoidectomy in children reduces pain in the immediate postoperative period, as well as to compare the effect of ice cream and diet at room temperature on post-tonsillectomy pain in children.

\section{Materials and methods}

Each patient's post-operative pain was evaluated and assessed by nursing staff prior to discharge using two reliable pain scale: FLACC scale (F: Face, L: Legs, A: Activity, C: Cry, C: Consolability) for patient less than seven years and Wong Baker pain scale (Face 0, very happy because he doesn't hurt, Face 1, hurts a little bit, Face 2, hurts a little more, Face 3, hurts even more, Face 4, hurts a whole lot, Face 5, hurts as much as you can imagine, although you do not have to be crying to fell this bad) for patient more than seven years.

\section{Results}

The ice cream intake is significantly associated with having no pain (p-value 0.014). In univariate regression, compared to preschool, school-aged children have significant effect with the ice cream intake postoperatively $(\mathrm{OR}=0.286$, $\mathrm{p}$-value 0.039$)$ while sex and instrument used to assess pain score were having no significant effect with the ice cream intake postoperatively.

Received 06/16/2020

Review began 06/29/2020 Review ended 06/29/2020 Published 07/09/2020

() Copyright 2020

Albeladi et al. This is an open access article distributed under the terms of the Creative Commons Attribution License CC-BY 4.0., which permits unrestricted use, distribution, and reproduction in any medium, provided the original author and source are credited.

\section{Conclusion}

Further research is needed in order to validate the effectivity of ice cream intakes after tonsillectomy in our region.

Categories: Otolaryngology
Keywords: ice cream, tonsillectomy, postoperative, pain, children

\section{Introduction}

The first removal of the tonsils was reported by the Greek physician Celsus about 2000 years ago. Celsus described his surgical procedure as scratching around the tonsils, releasing, and then removing them. He used vinegar and milk for hemostasis to reduce hemorrhage [1]. Tonsillectomy is still the most commonly performed surgical procedure for children in the United States with more than 530,000 procedures conducted annually. The most common indications of tonsillectomy are sleep-disordered breathing, tonsillitis, and peritonsillar abscess [1].

The most widely used technique to perform this operation is cold dissection method in which scalpel or surgical knife is utilized. After tonsillectomy, children should tolerate sore throats for one to two weeks and mostly experience referred pain in the ear. Acetaminophen is usually prescribed in order to control pain. The administration of steroids can also reduce pain and nausea [1].

Currently, a single dose of dexamethasone is recommended during the surgery. The post-tonsillectomy pain can lead to a decrease in fluid and food intake, followed by dehydration, which can slow down the repair process and make pain control harder. Different groups of analgesics have their own side effects. Therefore, the consideration of non-pharmacological ways to control pain can be of great value [1]. 


\section{Cureus}

\section{Materials And Methods}

A total of 50 children within the age range of 3-15 years who underwent tonsillectomy were randomly assigned into two groups - group 1 with ice cream served to them and group 2 with a room-temperature diet served to them postoperatively. Each patient's post-operative pain was evaluated and assessed by nursing staff prior to discharge using two reliable pain scale: FLACC scale (F: Face, L: Legs, A: Activity, C: Cry, C: Consolability) for patient less than seven years (Appendices), and Wong Baker pain scale (Face 0, very happy because he doesn't hurt, Face 1, hurts a little bit, Face 2, hurts a little more, Face 3, hurts even more, Face 4, hurts a whole lot, Face 5, hurts as much as you can imagine, although you do not have to be crying to fell this bad) for patient more than seven years (Appendices) $[2,3]$.

\section{Results}

A total of 50 children underwent tonsillectomy were enrolled in this study. Table 1 presents the baseline characteristics of children. Age range was from 6 to 13 years (mean $6.3 \pm 02.9$ ). A high proportion of patients were boys (64.0\%). Those who received ice cream postoperatively (case group) were $58 \%$ while those who did not receive ice cream (control group) were $42 \%$. FLACC scale was the instrument used to measure pain for the preschool children (60\%) whereas Wong Baker scale was the instrument used for school-aged children (40\%). Only four cases had shown an indication of pain based on the instrument where almost all of the patients had shown oral intake tolerance (96\%) whereas most of them discharged home from day case surgery (98\%). 


\section{Cureus}

\section{Study data}

N (\%) $(n=50)$

Age group in years

Preschool ( $3-6$ years)

$30(60.0 \%)$

School-aged child ( $7-13$ years $)$

Sex

Boy

Girl

$32(64.0 \%)$

$18(36.0 \%)$

Patients received ice cream post-operatively

Yes

No

$21(42.0 \%)$

Instruments used to assess pain score

FLACC scale ( $<7$ years old)

Wong Baker scale ( $\geq 7$ years old)

$20(40.0 \%)$

Level of Pain

With pain

$4(8.0 \%)$

No pain

$46(92.0 \%)$

Patients oral intake tolerance

Yes

$48(96.0 \%)$

No

$2(4.0 \%)$

Patients discharged home from day case surgery

Yes

$49(98.0 \%)$

No

$1(2.0 \%)$

TABLE 1: Baseline characteristics of patients

When measuring the association between ice cream intake postoperatively and the baseline characteristics of patients, we found that school-aged children were significantly more in the ice cream intake group ( $p$ value 0.035 ). Ice cream intake was significantly associated with having no pain (p-value 0.014 ). The distribution of ice cream intakes was higher in boys compared to girls but no association was found (Table 2). 


\section{Cureus}

\begin{tabular}{|c|c|c|c|}
\hline \multirow{2}{*}{ Factor } & \multicolumn{2}{|l|}{ Ice Cream Intake } & \multirow{2}{*}{ P-value $\$$} \\
\hline & Yes, N (\%) (n = 29) & No, $N(\%)(n=21)$ & \\
\hline \multicolumn{4}{|l|}{ Age group in years } \\
\hline Preschool & $21(72.4 \%)$ & $9(42.9 \%)$ & \multirow{2}{*}{$0.035^{* *}$} \\
\hline School-aged child & $8(27.6 \%)$ & $12(57.1 \%)$ & \\
\hline \multicolumn{4}{|l|}{ Sex } \\
\hline Boy & $19(65.5 \%)$ & $13(61.9 \%)$ & \multirow{2}{*}{0.793} \\
\hline Girl & $10(34.5 \%)$ & $8(38.1 \%)$ & \\
\hline \multicolumn{4}{|c|}{ Instrument used to assess pain score } \\
\hline FLACC scale & $19(65.5 \%)$ & $11(52.4 \%)$ & \multirow{2}{*}{0.349} \\
\hline Wong Baker scale & $10(34.5 \%)$ & $10(47.6 \%)$ & \\
\hline \multicolumn{4}{|l|}{ Level of pain } \\
\hline With pain & 0 & 4 (19.0\%) & \multirow{2}{*}{$0.014^{* *}$} \\
\hline No pain & $29(100 \%)$ & $17(81.0 \%)$ & \\
\hline \multicolumn{4}{|c|}{ Patient oral intake tolerance } \\
\hline Yes & $28(96.6 \%)$ & 20 (95.2\%) & \multirow{2}{*}{0.815} \\
\hline No & $1(3.4 \%)$ & $1(4.8 \%)$ & \\
\hline
\end{tabular}

TABLE 2: Association between ice cream intake postoperatively and the baseline characteristics of patients $(n=50)$

$\S$ P-value has been calculated using chi square test.

** Significant at $\mathrm{p} \leq 0.05$ level.

In univariate regression, compared to preschool, school-aged children had significant effect with the ice cream intake postoperatively $(\mathrm{OR}=0.286$, $\mathrm{p}$-value 0.039$)$ while sex and instrument used to assess pain score had no significant effect with the ice cream intake postoperatively (Table 3). 


\section{Cureus}

\begin{tabular}{|c|c|c|c|}
\hline Factor & Odds Ratio & $95 \% \mathrm{Cl}$ & P-value \\
\hline \multicolumn{4}{|l|}{ Age group in years } \\
\hline Preschool & Ref & & \multirow{2}{*}{0.039 ** } \\
\hline School-aged child & 0.286 & $0.087-0.937$ & \\
\hline \multicolumn{4}{|l|}{ Sex } \\
\hline Boy & Ref & & \multirow{2}{*}{0.793} \\
\hline Girl & 0.855 & $0.266-2.748$ & \\
\hline \multicolumn{4}{|c|}{ Instrument used to assess pain score } \\
\hline FLACC scale & Ref & & \multirow{2}{*}{0.351} \\
\hline Wong Baker scale & 0.579 & $0.184-1.826$ & \\
\hline
\end{tabular}

\section{TABLE 3: Binary regression analysis to predict the effect of ice cream intake from the baseline characteristics of patients $(n=50)$}

$\mathrm{Cl}$ - Confidence Interval.

** Significant at $p \leq 0.05$ level.

\section{Discussion}

Various forms of complication might happen during the course of surgery or right after tonsillectomy and the most commonly known among them was pain. Pharmacological agents such as analgesic have limited time of effects and might causes adverse effect. Children also complained of swallowing some agents that left a bad taste to their mouth. Different recommendations have been proposed for the management of pain. Some of them were: intravenous hydration, diet at room temperature, steroids or antibiotics and cold diet. The purpose behind this study is to assess whether the use of ice cream after tonsillectomy with or without adenoidectomy in children reduces pain in the immediate postoperative period. Furthermore, we want to compare the effect of ice cream and diet at room temperature on post-tonsillectomy pain in children. In this study, we randomly selected 58\% patients for ice cream intake while for diet at room temperature $42 \%$ patients were selected. This selection criteria were also in accordance to the paper published by Meybodian et al. [1]. The study was about to measure the "effect of cold diet and diet at room temperature on posttonsillectomy pain in children" where they divided the cases into two groups such as: $48.6 \%$ children were provided with cold-served diet (case group) and 51.4\% were provided diet in room temperature (control group). A single-blinded, randomized controlled trial published in United Kingdom examined the use of icelollies for pain relief post-pediatric tonsillectomy [4]. They also divided 88 patients into two group such as: 47 cases allocated to receive an ice-lolly and 41 cases not to receive ice-lolly, which was also corroborated with our method. In South Korea, they divided patients into two groups equally where group 1 received coldwater cooling of the tonsillar fossa (20 cases) whereas group 2 did not receive cold-water cooling, which also supported our criteria [5]. This had also been indicated in a study published in Turkey, where they divided their cases into two group such as, group 1 as irrigated group and group 2 as control group [6].

In this study, we used the Face, Legs, Activity, Cry, Consolability (FLACC) scale to assess the pain of the preschool group of patients. The scale is scored in a range of $0-10$ with 0 representing no pain. The scale has five criteria, each of which are assigned a score of 0,1 or 2 [2]. On the other hand, we utilized Wong-Baker Faces Pain Rating scale to measure the pain for school-aged children [3]. This is a pain scale that was developed by Donna Wong and Connie Baker. The scale shows a series of faces ranging from a happy face at 0 , or "no hurt", to a crying face at 10 , which represents "hurts like the worst pain imaginable". Based on the faces and written descriptions, the patient chooses the face that best describes their level of pain. FLACC pain scale had also been utilized in a study published by Meybodian et al. [1]. They measured the pain prior to oral diet initiation after the operation, before the second acetaminophen dose, before the next day breakfast and before discharge. Moreover, in UK, they used Modified Children's Hospital of Eastern Ontario Pain Scale (Mcheops) to assess the pain of post-pediatric tonsillectomy [4]. The in-charge nursing staff assessed the pain of the patients at interval time of 15, 30, 60 minutes and 4 hours post-pediatric tonsillectomy while visual analogue scale (VAS) was the instrument employed to assess the pain of children by the papers published in Korea and Turkey [5-6]. 


\section{Cureus}

Furthermore, when measuring the effectivity of ice cream intakes among children who underwent tonsillectomy, we found that ice cream intake is significantly associated with having no pain. In the developed countries such as UK, Korea and Turkey, they documented that the healing process was significantly improved upon the intakes of ice lollies, receiving of cold-water cooling and cooling the tonsillar fossae, and they measured the pain in a series of period of time [5-6]. On the other notes, in a paper published in the United States, they reported that the administration of cold things by mouth was the number one nonpharmacologic strategy for pain relief identified by $59.5 \%$ of children [7]. The use of popsicles was named specifically as an effective intervention. They further elaborated that $10.1 \%$ of the children used soft foods which resulted in decreasing of pain and 5.1\% of them reported that the application of external cold packs improved pain relief. These findings supported that cold drinks are one of the best methods in the management of pain post-tonsillectomy.

\section{Conclusions}

This study revealed that ice cream intake is significantly effective among children who underwent tonsillectomy. Further research is needed in order to validate the effectivity of ice cream intakes after tonsillectomy in our region.

\section{Appendices}

The following table provides the criteria for the FLACC Behavioural pain scale.

\begin{tabular}{|c|c|c|c|}
\hline Behaviour & 0 & 1 & 2 \\
\hline Face & No particular expression or smile & $\begin{array}{l}\text { Occasional grimace or frown, } \\
\text { withdrawn, disinterested }\end{array}$ & $\begin{array}{l}\text { Frequent to constant quivering } \\
\text { chin, clenched jow }\end{array}$ \\
\hline Legs & Normal position or relaxed & Uneasy, restless, tense & Kicking or legs drawn up \\
\hline Activity & $\begin{array}{l}\text { Lying quietly, normal position, } \\
\text { moves easily }\end{array}$ & $\begin{array}{l}\text { Squirming, shifting, back and } \\
\text { forth, tense }\end{array}$ & Arched, rigid or jerking \\
\hline Cry & No cry (awake or asleep) & $\begin{array}{l}\text { Moans or whimpers; occasional } \\
\text { complaint }\end{array}$ & $\begin{array}{l}\text { Crying steadily, screams, sobs, } \\
\text { frequent complaints }\end{array}$ \\
\hline Consolability & Content, relaxed & $\begin{array}{l}\text { Reassured by touching, hugging } \\
\text { or being talked to, distractible }\end{array}$ & Difficult to console or comfort \\
\hline
\end{tabular}

FIGURE 1: FLACC pain scale

FLACC = F: Face, L: Legs, A: Activity, C: Cry, C: Consolability

Developed for young patients to communicate how much pain they are feeling

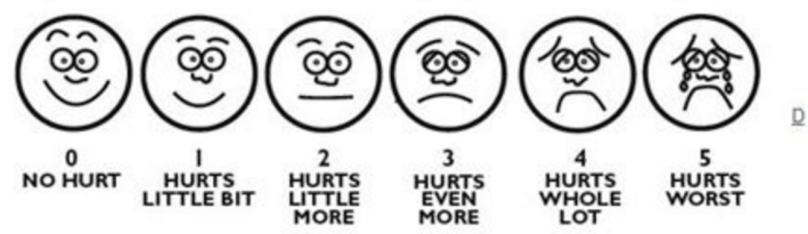

\section{Instructions}

Explain to the child that each face is for a person who feels happy because he has no pain (hurt) or sad because he has some or a lot of pain.

Face 0 is very happy because he doesn't hurt at all

Face 1 hurts just a little bit.

Face 2 hurts a little more.

Face 3 hurts even more.

Face 4 hurts a whole lot more.

Face 5 hurts as much as you can imagine, although you do not have to be crying to feel this bad.

Ask the child to choose the face that best describes how he/she is feeling.

Reference: Mockenberry MJ, Wison D, Winkelstein ML- Wong's Essentials of Pediatic Nursing, ed, 7, St Lovis, 2005 p. 1259

Used with permission. Mosty

FIGURE 2: Wong Baker FACES pain rating scale 


\section{Additional Information}

Disclosures

Human subjects: Consent was obtained by all participants in this study. Ohud Hospital issued approval ERC-08072019-279. Animal subjects: All authors have confirmed that this study did not involve animal subjects or tissue. Conflicts of interest: In compliance with the ICMJE uniform disclosure form, all authors declare the following: Payment/services info: All authors have declared that no financial support was received from any organization for the submitted work. Financial relationships: All authors have declared that they have no financial relationships at present or within the previous three years with any organizations that might have an interest in the submitted work. Other relationships: All authors have declared that there are no other relationships or activities that could appear to have influenced the submitted work.

\section{References}

1. Meybodian M, Dadgarnia M, Baradaranfar M, Vaziribozorg S, Mansourimanesh M, Mandegari M, Eslami NS: Effect of cold diet and diet at room temperature on post-tonsillectomy pain in children . Iran J Otorhinolaryngol. 2019, 31:81-86.

2. Merkel SI, Voepel-Lewis T, Shayevitz JR, Malviya S: The FLACC: a behavioral scale for scoring postoperative pain in young children. Pediatr Nurs. 1997, 23:293-297.

3. Baker CM, Wong DL: Q.U.E.S.T: a process of pain assessment in children (continuing education credit) . Orthop Nurs. 1987, 6:11-21.

4. Sylvester DC, Rafferty A, Bew S, Knight LC: The use of ice-lollies for pain relief post-paediatric tonsillectomy. A single-blinded, randomised, controlled trial. Clin Otolaryngol. 2011, 36:566-570. 10.1111/j.1749-4486.2011.02410.x

5. Shin JM, Byun JY, Baek BJ, Lee JY: Effect of cold-water cooling of tonsillar fossa and pharyngeal mucosa on post-tonsillectomy pain. Am J Otolaryngol. 2014, 35:353-356. 10.1016/j.amjoto.2014.01.005

6. Karaca ÇT, Çelebi Ş, Oysu Ç, Çelik Ö: Does cooling the tonsillar fossae during thermal welding tonsillectomy have an effect on postoperative pain and healing?. Eur Arch Otorhinolaryngol. 2013, 270:363-366. 10.1007/s00405-012-2129-x

7. Sutters KA, Savedra MC, Miaskowski C, Holdridge-Zeuner D, Waite S, Paul SM, Lanier B: Children's expectations of pain, perceptions of analgesic efficacy, and experiences with nonpharmacologic pain management strategies at home following tonsillectomy. J Spec Pediatr Nurs. 2007, 12:139-148. 10.1111/j.1744-6155.2007.00107.x 